\title{
PERFORMANCE EVALUATION OF MULTIBED ADSORBENT ON REMOVAL OF HEXAVALENT CHROMIUM THROUGH VARIOUS KINETIC MODELS
}

\author{
L. M. LALITHA ${ }^{1 *}$, S. MARIRAJ MOHAN ${ }^{2}$ \\ ${ }^{1}$ Department of Civil Engineering, Alagappa Chettiar College of Engineering and Technology, \\ Karaikudi - 630003, Tamilnadu, India \\ ${ }^{2}$ Alagappa Chettiar Government College of Engineering and Technology, \\ Karaikudi - 630003, Tamilnadu, India
}

Received 7 June 2017; accepted 24 April 2018

\begin{abstract}
In this study, an idea of using multiple layers of adsorbents in adsorption column is proposed for treatment of synthetic wastewater for removal of $\mathrm{Cr}(\mathrm{VI})$ ions. In the present study, an effort has been made to study and compare the performance of fixed bed column with single bed adsorbent (RH only) and multi bed adsorbent of Rice Husk (RH), Saw Dust (SD) and Coir Dust (CD) in removal of Cr(VI) from synthetic wastewater and arrive at the parameters of the adsorption column that are useful for process design. From the characterization studies, it has been observed that carbon, aluminium and silica were the major components of the three natural adsorbents studied. It was found that, for better heavy metal removal, natural adsorbents with a percentage of fineness of around $54 \%$ could be used in adsorption studies. From the breakthrough curves of single bed and multi bed adsorption columns, it was evident that the multi bed adsorption column performed better. The time taken to achieve the breakthrough point and the exhaustion point in multi bed column is 2.5 times and 1.9 times greater than the time taken by single bed adsorption studies respectively. It was observed that in multi bed adsorption column, at greater bed depths, the significant increase in metal uptake capacity was due to the increase in contact time. Kinetic models viz. Thomas model, Yoon-Nelson model and Bed Depth Service Time model (BDST) were used to predict the performance of the column and sum of squares (SS) error analysis was carried out to test the accuracy of model equations. Higher $\mathrm{R}^{2}$ value and smaller SS value obtained from Thomas model proves that it is suitable to explain the adsorption of $\mathrm{Cr}(\mathrm{VI})$ in single and multi bed adsorption column of natural adsorbents. Experimental data fitted well with BDST model where $\mathrm{R}^{2}=0.997$. From the cost analysis, multi bed adsorption column was proven to be economical and confirmed that the locally and abundantly available agricultural wastes viz. RH, SD and CD could be used as an alternate to commercially available activated carbon for the removal of $\mathrm{Cr}(\mathrm{VI})$ from synthetic wastewater.
\end{abstract}

Keywords: BDST model, multi bed adsorption column, natural adsorbents, single bed adsorption column, Thomas model, Yoon-Nelson model.

\section{Introduction}

As a result of fast urbanization and industrialization, heavy metal contamination is a severe setback and its treatment is alarming due to their recalcitrance and its persistent presence in the environment. Industries such as automobile, mining, electroplating, iron-steel, plating, tanneries and battery industries utilize most harmful substances containing heavy metals such as cadmium, chromium, copper, nickel, arsenic, lead and zinc (Argun \& Dursun, 2008). Subsequently, these heavy metals are discharged into the natural streams from the effluents released by the industries. Due to their highly soluble nature in the aquatic environment, heavy metals can be biomagnified by getting absorbed onto aquatic organisms (Alluri et al., 2007; Meena, Kadirvelu, Mishra, Rajagopal, \& Nagar, 2008).

Contamination of water by heavy metals, in particular chromium has much distress to society and regulation authorities around the world. Various industries like metal plating, leather tanning, textile dyeing, paints and pigments extensively use chromium thereby resulting in enormous quantity of chromium rich wastewater discharge into the environment as trivalent and hexavalent chromium ions. Hexavalent chromium compounds are carcinogenic and noxious whereas toxicity of Trivalent Chromium is relatively meagre and it is not a problem

${ }^{*}$ Corresponding author. E-mail: lalicivill@gmail.com 
for the environment (Yue, Bender, Wang, \& Economy, 2009). Presence of chromium causes various health effects like skin rashes, respiratory problems, haemolysis, weakened immune systems, alteration of genetic material, lung cancer, kidney and liver damage, pulmonary fibrosis and acute renal failure (Alluri et al., 2007). Generally, the treatment methods adopted for removal of heavy metals include chemical precipitation, ion exchange, distillation, sedimentation, oxidation, reduction, electrochemical treatment, evaporation, membrane filtration, coagulation and flocculation, floatation, electro deposition, reverse osmosis, etc. (Fu \& Wang, 2011; Zwain, Vakili, \& Dahlan, 2014). On the other hand, these techniques have the disadvantages of low removal efficiency, high cost and secondary contamination problems. Adsorption is the generally used method in physicochemical wastewater treatment. Commonly used adsorbents are activated carbon, silicon polymers and kaolin in the water and wastewater treatment plants. For developing countries the usage of ion exchange resins and activated carbon are not appropriate because of their high operational and capital cost. In recent years, researchers focus on the investigation of some unconventional methods and low cost materials for removing heavy metal ions from industrial waste waters (Vempati et al., 1995). This study aims at finding an efficient natural adsorbent for the removal of the chromium from polluted water.

In general, adsorbents are assumed to be "low cost" if little processing is required before use, or is a waste material or by-product from industry or abundantly available in nature. Certainly, increased sorption capacity may balance additional processing cost. Certain industrial wastes or natural materials with a tendency for adsorbing heavy metals can be engaged and disposed of with little cost. In recent years, research interest has been initiated in finding low cost alternatives for commercially available activated carbon. Hence, lots of research work has been concentrated on using agricultural by-products and wastes as an alternative to commercially available adsorbent. These adsorbents include low cost agricultural waste by-products such as sugarcane baggase (Mohan \& Singh, 2002; Khan, Ali, \& Ayub, 2001), Rice husk (Srinivasan, Balasubramanian, \& Ramakrishna, 1988; Munaf \& Zein, 1997; Suemitsu, Uenishi, Akashi, \& Nakano, 1986; Ajmal, Rao, Anwar, J. Ahmad, \& R. Ahmad, 2003), Sawdust (Horisawa et al., 1999; Selvi, 2001), Coconut husk (Tan, Ooi, \& Lee, 1993), etc., just to mention a few.

In the present study, Rice Husk (RH), SawDust (SD) and Coir Dust (CD) are chosen as natural adsorbents since they are abundantly available in local areas of developing countries like India, highly cost effective and efficient in removing heavy metals like $\mathrm{Cr}(\mathrm{VI})$. These have attracted particular attention because these waste represents resources which are not used at its fullest and in many cases cause serious disposal problems. Sawdust is one of the most appealing agricultural waste material for removing heavy metals from water and waste water (Shukla,
Zhang, Dubey, Margrave, \& Shukla, 2002). Some reports on removal of Chromium (VI) ions using treated sawdust are available, but information on raw sawdust is limited.

Rice husk is one of the most commonly available agricultural wastes in many rice producing countries all over the world. Worldwide, approximately 600 million tonnes of rice paddy is produced each year. On an average, $20 \%$ of the rice paddy is husk, giving an annual total production of 120 million tonnes. Rice husk is the outer covering of paddy and accounts for $20-25 \%$ of its weight. The annual generation of rice husk in India is in the range of 18-22 million tonnes (Vempati et al., 1995). Rice husk, an abundant biomaterial, is capable of removing heavy metals and can be considered as an efficient and low-cost adsorbent for heavy metal removal. Conclusions from earlier studies on rice husk also suggested effectiveness in removing chromium, such as rice husk ash, phosphate-treated rice husk, and sodium carbonate treated rice husk.

Coconut coir dust is one of the agricultural waste products often used as adsorbent in waste water treatment. Its availability all year round and its abundance in the environment makes it a good source of adsorbent for metal ion removal from aqueous solution. It is the light, fluffy material that falls off from the thick mesocarp of coconut fruit when shredded during coir processing. The three remarkable properties of coir dust that enhances its effectiveness as adsorptive/ion exchange capacities include good structural stability, high water absorptive and high porous nature (Kadirvelu, Thamaraiselvi, \& Namasivayam, 2001). Its constituents include lignin $-36.15 \%$, cellulose $33.61 \%$, pentosana $-29.27 \%$, ash $-0.61 \%$, dry basis (Ajmal et al., 2003; Jeyaseeli \& Ray, 2010). The other constituents are kemi celluloses and extractives. These extractives contain tannins, pectins, with polyphenolic, carboxyl and hydroxyl groups. Lignins and cellulose in the coir affords its adsorptive/ion exchange properties. The porous structure of the coir dust allows it to absorb large amount of water but still, remain insoluble very much like any synthetic hydrogel (Bishnoi, Bajaj, Sharma, \& Gupta, 2004).

The present study has focused on adsorption of $\mathrm{Cr}(\mathrm{VI})$, given its dangerous impact on health and the environmental future of the disposal site, and its significant presence in the industrial wastewater. The natural adsorbents were used without any modification (chemical or physical) in order to keep the process cost low.

The aim of this project is to efficiently remove heavy metal from the synthetic wastewater by using multilayer media of natural adsorbents viz. rice husk (RH), saw dust (SD) and coir dust (CD). In most of the previous works carried out, wastewater treatment with single bed adsorbent has been carried out (Kumar \& Bandyopadhyay, 2006; Mohan \& Sreelakshmi, 2008; Li \& Champagne, 2009; Sharma, Ayub, \& Tripathi, 2013), but the effect of multilayer adsorbent using low cost materials on wastewater treatment has more potential to be explored. Multibed as the name suggests it has an advantage of using three different media in same bed depth acted as a single unit. 
They provide space for finding combination which brings maximum removal and as the materials differ, other efficient purification process like filtration also may occur which is the added advantage. Combination of high porosity and specific surface area adsorbent can be used to achieve maximum removal. Thus the basic idea is that multilayer adsorbent provides place for efficient removal of heavy metal along with other impurities. Novelty of the present study is significant, because an attempt has been made to study and compare the efficiency in removal of $\mathrm{Cr}(\mathrm{VI})$ from synthetic wastewater in packed bed column with single layer adsorbent (RH only) and multilayer adsorbent comprised of natural adsorbents $(\mathrm{RH}, \mathrm{CD}, \mathrm{SD})$.

Most of the studies mentioned above were carried out in batch mode, which is applicable only to wastewater treatment in small quantities. The effectiveness of metal-adsorbent system can be quantified only by using the sorption capacity parameter acquired by conducting a batch experiment. Data recorded using batch conditions are generally not directly applicable for scale up process. As the contact time provided to achieve equilibrium in batch operation is so long, it cannot be practically applied to full scale applications. Hence the contact time required for the adsorbate to achieve equilibrium has to be assessed by carrying out the column studies. Therefore, it becomes very important to explore the efficiency of the multilayer media of adsorbents and their feasibility for the removal of heavy metals to be studied in all respects.

Based on the aforesaid discussion the objectives of the present study have been formulated as follows:

To determine the chemical composition of natural adsorbents through EDX and to determine the efficacy of single layer adsorbent adsorption column using RH as adsorbent on removal of $\mathrm{Cr}(\mathrm{VI})$ from synthetic wastewater.

To determine the influence of the effect of multilayer media of $\mathrm{RH}, \mathrm{SD} \& \mathrm{CD}$ on $\mathrm{Cr}(\mathrm{VI})$ removal from the synthetic wastewater.

Evaluation of kinetic models viz. Thomas model, BDST model and Yoon-Nelson model befitting to experimental study data.

Cost comparison of the single and multi bed adsorption column with chosen natural adsorbents.

\section{Materials and methods}

\subsection{Collection of adsorbents}

Rice husk (RH) was collected from the nearby local rice mill located at Aranthangi, Tamil Nadu, India. Saw dust (SD) and Coir Dust (CD) was obtained from a wood workshop and commercial coconut shop in the market at Karaikudi, Tamil Nadu, India respectively. Then, they were washed separately in double distilled water until the impurities were removed and then oven dried at $60^{\circ} \mathrm{C}$ for a day and brought back to room temperature by keeping them in desiccators. They were sieved through different sizes of IS sieve and fraction of particles between $425 \mu \mathrm{m}$ and $600 \mu \mathrm{m}$ were selected (Kumar \& Bandyopadhyay,
2006). These fractions of particles were herein referred to as RH, SD and CD samples and are used in upcoming experimental works.

\subsection{Preparation of synthetic wastewater}

All chemicals used are of analytical grade. The wastewater that was used was prepared synthetically in the laboratory by taking $0.565 \mathrm{gm}$ of potassium dichromate $\left(\mathrm{K}_{2} \mathrm{Cr}_{2} \mathrm{O}_{7}\right)$ and made up to $1000 \mathrm{ml}$ in order to get the concentration of $\mathrm{Cr}(\mathrm{VI})$ as $200 \mathrm{ppm}$ and, finally, solutions of metals used for calibration procedures were tested in Atomic Absorption Spectrometry. The $200 \mathrm{mg} / \mathrm{L}$ of $\mathrm{Cr}(\mathrm{VI})$ has been taken to imitate effluent from steel plant.

Sample we considered for this study was artificial one. In this project it is aimed at imitating steel plant effluent which has the heavy metal concentration in the prescribed range. Having taken real sample for this study, it could have produced intermediate compound as the sample required storage for some period of time during the span of the study. Had it been to formation of the unwanted intermediate compound, effluent prediction could not be good as mathematical model was used to evaluate performance of the adsorbent. Furthermore, real effluent steel plant effluent contains suspended and dissolved solids. If we considered real sample, it is necessary to provide preliminary treatment to exclude the solids. But this study exclusively focuses on removal of heavy metals using natural adsorbents. However, in real field, after eliminating the solids and converting the waste waster containing only heavy metal, the result of this study could be used.

\subsection{Characterization of adsorbents}

Sieve Analysis was done for all the three natural adsorbents to determine their particle size distribution. IS sieve of sizes $4.75 \mathrm{~mm}, 2.36 \mathrm{~mm}, 2 \mathrm{~mm}, 1.18 \mathrm{~mm}, 600 \mu \mathrm{m}$, $425 \mu \mathrm{m}, 300 \mu \mathrm{m}, 150 \mu \mathrm{m}, 75 \mu \mathrm{m}$ and a bottom pan were used. $250 \mathrm{~g}$ weighed sample was placed in sieve and was subsequently covered by the sieve lid. The manual shaking mechanism for 10 minutes in up-down movements and left right directions was adopted. The material collected in each sieve was weighed using weigh balance. The readings were tabulated and the percentage of fineness was calculated.

Energy-Dispersive X-ray (EDX) microanalysis test was used to determine the chemical composition of all three natural adsorbents. The sample in powdered form was analysed under low vacuum without any previous preparation. Atomic Absorption Spectrophotometer (Hitachi Z8270) was used to determine $\mathrm{Cr}(\mathrm{VI})$ concentration in synthetic wastewater samples and experimental effluent sample.

\subsection{Experimental setup}

The adsorption with natural adsorbents was studied with the aim of treating the industrial wastewater especially from steel industries. The $\mathrm{Cr}(\mathrm{VI})$ concentration in steel 
industrial wastewater was found to be around $200 \mathrm{mg} / \mathrm{L}$ (Bhattacharya, Mandal, \& Das, 2006). Thus, for the present study initial $\mathrm{Cr}(\mathrm{VI})$ concentration has been fixed at this level. The adsorption column used in this study is of $3 \mathrm{~cm}$ diameter; $30 \mathrm{~cm}$ bed height and $7.06 \mathrm{~cm}^{2}$ area. Specifications of column used in this study are given in Table 1. The column was packed by sandwiching adsorbents between two supporting layers of glass wool. The adsorbent with particle size $425 \mu \mathrm{m}-600 \mu \mathrm{m}$ was added from the top of the column, to form layers, each for a depth of $10 \mathrm{~cm}$ in the following order RH, SD and CD for multi bed adsorption column. The layers were arranged such that the adsorbent with greater specific gravity is at the bottom, and hence it tends to settle easily by gravity (Kumar, 2012). In single bed adsorption column, rice husk $(\mathrm{RH})$ is only filled as adsorbent for a depth of $30 \mathrm{~cm}$.

Table 1. Specifications of the column

\begin{tabular}{|c|c|c|}
\hline S. No. & Parameters & Values \\
\hline 1. & Column bed height & $30 \mathrm{~cm}$ \\
\hline 2. & Diameter of the column & $3 \mathrm{~cm}$ \\
\hline 3. & Height of the column & $55 \mathrm{~cm}$ \\
\hline 4. & Area of the column & $7.06 \mathrm{~cm}^{2}$ \\
\hline 5. & Volume of the column & $388.77 \mathrm{~cm}^{3}$ \\
\hline 6. & Initial $\mathrm{Cr}(\mathrm{VI})$ Concentration & $200 \mathrm{mg} / \mathrm{l}$ \\
\hline \multirow[b]{2}{*}{7.} & $\begin{array}{l}\text { Mass of adsorbent in column: } \\
\text { a) Single bed adsorption column - } \\
\text { RH }\end{array}$ & $19.22 \mathrm{~g}$ \\
\hline & $\begin{array}{l}\text { b) Multi bed adsorption column: } \\
\text { 1. CD } \\
\text { 2. SD } \\
\text { 3. RH }\end{array}$ & $\begin{array}{l}9.21 \mathrm{~g} \\
10.15 \mathrm{~g} \\
6.00 \mathrm{~g}\end{array}$ \\
\hline 8. & Flow rate & $9.50 \mathrm{ml} / \mathrm{min}$ \\
\hline
\end{tabular}

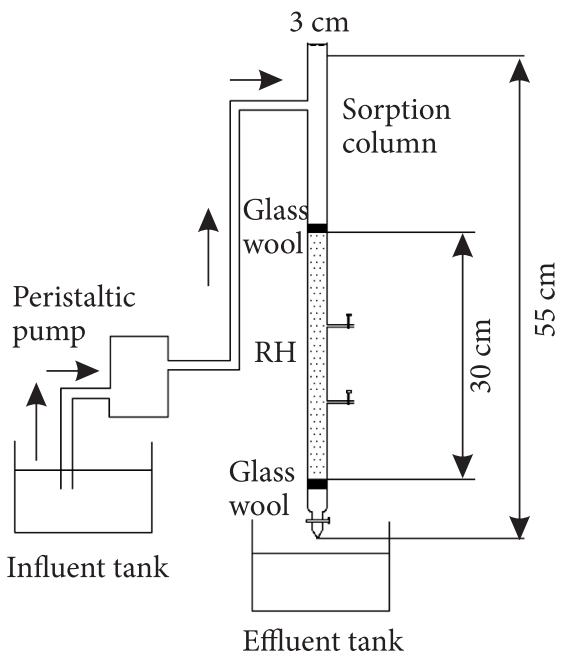

a)
In order to avoid the escape of bed material through the effluent the upper and lower portions of the adsorbent were covered with glass wool. The schematic sketch of the single bed and multi bed column study is shown in Figure $1 \mathrm{a}$ and $\mathrm{b}$ respectively. About 60 Lof synthetic wastewater was filled in a bucket, and a peristaltic pump controlled the continuous down-flow rate, which was maintained as $9.5 \mathrm{~mL} / \mathrm{min}$. The samples were collected in 3 valves at each bed height of adsorbent at the time interval of 30 minutes for multi bed adsorption column. For single bed, effluent from bottom alone has been collected for every $30 \mathrm{~min}$ utes. All the samples collected were processed using AAS (Z8270). The reproducibility was ensured by taking replicate samples. Resultant deviations were not much more $( \pm 3 \%)$.

\subsection{Modelling of column data}

In the present study, an initiative has been taken to study and compare the performance of fixed bed column with single bed adsorbent (RH only) and multilayer adsorbent of RH, SD and CD, in removal of Cr(VI) from synthetic wastewater and arrive at the adsorption column design parameters. Kinetic models viz. Thomas model, Yoon-Nelson model and Bed Depth Service Time model (BDST) were used to predict the performance of the column and sum of squares (SS) error analysis was carried out to examine the accuracy of model equations. These models were used to fit the dynamic flow experimental data performed in the fixed-bed column to determine the characteristic parameters of the column and to predict the breakthrough curves.

\subsubsection{Bed Depth Service Time (BDST) model}

The BDST is a model which predicts predicting the relationship between service time $t$ and depth X (Aksu \&

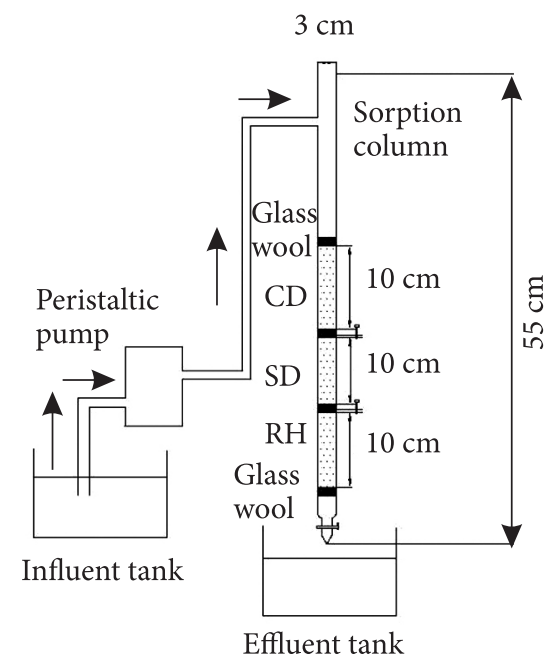

b)

Figure 1. Schematic diagram of adsorption column unit for lab scale study a) single bed adsorption column set-up with $\mathrm{RH}$ as adsorbent measuring $30 \mathrm{~cm}$ thickness and b) multi bed adsorption column set-up with RH, SD \& CD as adsorbents each of $10 \mathrm{~cm}$ 
Gönen, 2004). In this model, forces like external mass transfer resistance and intra particle diffusion are assumed to be negligible. The adsorbate is assumed to be adsorbed directly onto the adsorbent surface (Han et al., 2009). This BDST model was used for the estimation of characteristic parameters such as the adsorption rate constant $k_{a d s}$ and adsorption capacity $N_{0}$. The original BDST model was carried out by (Bohart \& Adams, 1920) and given in Eq. (1)

$$
\ln \left[\frac{C_{0}}{C_{b}}-1\right]=\ln \left(e^{\left(k_{a d s} N_{0} / V\right) X}-1\right)-k_{a d s} C_{0} t_{b} .
$$

Later, Hutchins proposed a linear relationship between the column bed depth $(\mathrm{X})$ and service time $\left(t_{b}\right)$ :

$$
t_{b}=\frac{N_{0}}{C_{0} V} X-\frac{1}{k_{a d s} C_{0}} \ln \left[\frac{C_{0}}{C_{b}}-1\right],
$$

where $t_{b}$ is the service time at breakthrough point (h); $N_{0}$ is the dynamic bed capacity $\left(\mathrm{mg} \mathrm{l}^{-1}\right) ; X$ is the packedbed column depth $(\mathrm{cm}) ; V$ is the linear flow rate $\left(\mathrm{cm} \mathrm{h}^{-1}\right)$ defined as the ratio of volumetric flow rate $Q_{v o l}\left(\mathrm{~cm}^{3} \mathrm{~h}^{-1}\right)$ to the cross-sectional area of the bed $S_{c}\left(\mathrm{~cm}^{2}\right) ; C_{0}$ and $C_{b}$ are respectively, the inlet and breakthrough metal ions concentration $\left(\mathrm{mg} \mathrm{l}^{-1}\right) ; k_{\text {ads }}$ the adsorption rate constant $\left(\mathrm{mg}^{-1} \mathrm{~h}^{-1}\right)$. Eq. (2) known as bed depth service time (BDST) equation. It is in the form of a straight line equation Eq. (3) whose slope (a) and intercept (b) are evaluated from the plot of $t_{b} V s X$, which can be used to determine $k_{a d s}$ and $N_{0}$ for a given adsorbent bed depth.

$$
t_{b}=a X-b,
$$

where, $\mathrm{a}=$ slope $=\frac{N_{0}}{C_{0} V}(\mathrm{~h} / \mathrm{cm})$

and

$$
b=\text { intercept }=\frac{1}{k_{a d s} C_{0}} \ln \left[\frac{C_{0}}{C_{b}}-1\right] .
$$

At time $t=0$, the bed depth which is required to ensure that the outlet effluent concentration does not exceed the $10 \%$ of initial influent concentration i.e., breakthrough concentration $\left(C_{b}\right)$ is known as critical bed depth $\left(X_{0}\right)$ which is calculated from Eq. (6).

$$
X_{0}=\frac{V}{k_{a d s} N_{0}} \ln \left(\frac{C_{0}}{C_{b}}-1\right) .
$$

The extension of BDST model can also be used to predict slope of the model for varying flow rate from $Q$ to $Q_{1}$, the modified slope value $\left(a^{1}\right)$ can be calculated from Eq. (7) where as the intercept remains unchanged as it depends on the inlet solute concentration $\left(C_{0}\right)$.

$$
a^{1}=\frac{a Q}{Q^{1}} .
$$

\subsubsection{Thomas model}

The behaviour of adsorption process taking place in fixedbed column is generally described by using Thomas model (Han et al., 2009). The experimental data obtained from continuous mode column study was used in Kinetic model developed by Thomas (1944) to determine the adsorption rate constant and the maximum solid concentration of $\mathrm{Cr}(\mathrm{VI})$ ions on adsorbent. The expression for Thomas model is represented as in Eq. (8):

$$
\frac{C_{t}}{C_{0}}=\frac{1}{1+\exp \left(\frac{k_{T H} q_{e} x}{Q}-k_{T H} C_{0} t\right)} \text {. }
$$

The Thomas rate constant $\left(\mathrm{k}_{\mathrm{TH}}\right)$ and bed capacity $\left(q_{e}\right)$ can be calculated from the plot of $\ln \left(C_{0} / C-1\right)$ against $t(\mathrm{~min})$ for a given flow rate using nonlinear regression analysis.

\subsubsection{Yoon-Nelson model}

Yoon-Nelson model is mathematically equivalent to Thomas model and it has been applied to a range of effluent concentrations between breakthrough and saturation time of the column (Bharathi \& Ramesh, 2013). It is based on the assumption that, the rate of decrease in probability of adsorption for each adsorbate molecule is proportional to the probability of adsorbate breakthrough on the adsorbent. Due to lack of complications, detailed data relating to characteristics of adsorbate such as, type of adsorbent and physical properties of adsorption bed are not required (Han et al., 2009). The Yoon-Nelson equation (Yoon \& Nelson, 1984) can be represented linearly as in Eq. (9):

$$
\ln \left(\frac{C_{t}}{C_{0}-C_{t}}\right)=K_{Y N} t-\tau K_{Y N},
$$

where $K_{Y N}$ is the Yoon-Nelson rate constant; $\tau$ is the time required for $50 \%$ adsorbate breakthrough and $t$ is breakthrough time. From the plot of $\ln \left[C /\left(C_{0}-C\right)\right]$ against $t$, the parameters $K_{Y N}$ and $\tau$ can be calculated using nonlinear regressive analysis.

\subsection{Error analysis}

During linear regressive analysis, usage of different formula to calculate $\mathrm{R}^{2}$ values would affect the accuracy more significantly. Therefore, to avoid such errors nonlinear regressive analysis is a better option (Han et al., 2009). Thus using least square of errors method in non-linear regression analysis, the parameters of different kinetic models were obtained. In order to confirm which model is better, error analysis was performed. The relative mathematical formula of $S S$ is represented as in Eq. (10).

$$
S S=\frac{\sum_{0}^{n}\left[\left(C_{t} / C_{0}\right)_{c}-\left(C_{t} / C_{0}\right)_{e}\right]}{N},
$$

where $\left(C_{t} / C_{0}\right)_{c}$ is the ratio of effluent and influent $\mathrm{Cr}(\mathrm{VI})$ concentrations obtained from calculation according to kinetic models, and $\left(C_{t} / C_{0}\right)_{e}$ is the ratio of effluent and influent $\mathrm{Cr}(\mathrm{VI})$ concentrations obtained from experiment, respectively; $N$ is the number of the experimental point. In order to confirm the best fit theoretical model for the adsorption 
system, it is necessary to analyze the data using $S S$, combined with the values of the determined coefficient $\left(R^{2}\right)$.

\section{Results and discussion}

\subsection{Size distribution of adsorbents}

The particle size distribution analysis was carried out as per fine analysis procedure prescribed by IS: 460-1962 ((Indian Standards Institution, 2016). The total mass of the taken sample was $500 \mathrm{~g}$ for each adsorbent. The weight of the particles retained were observed and tabulated from which cumulative $\%$ weight retained was calculated using the formula as in Eq. (12). Then, the percentage of fineness for all three adsorbents were calculated by using the formula as in Eq. (11). Particle size distribution and percentage of fineness of natural adsorbents are given in Table 2.

$$
\% \text { finesness }=100-\text { cumulative } \% \text { wt. retained, }
$$

where

$$
\text { Cumulative } \% \text { wt.retained }=100 \frac{\left(\sum \text { mass retained }\right)}{\text { Total mass of sample }} \text {. }
$$

The size distribution curve for $\mathrm{RH}, \mathrm{SD}$ and $\mathrm{CD}$ are as shown in the Figure 2. From the Figure 2, it was observed that the average particle size $\left(D_{10}\right)$ is $0.2 \mathrm{~mm}$ and $D_{60}$ is $0.6 \mathrm{~mm}$. Uniformity coefficient $\left(C_{u}\right)$ was calculated using formula given in Eq. (13) and found to be 3 .

$$
\text { Uniformity Coefficient, } C_{u}=\frac{D_{60}}{D_{10}},
$$

where, $D_{60}=$ diameter of the particles for which $60 \%$ of the particles are finer and $40 \%$ of the particles are coarser than $D_{60}$.

$D_{10}=$ diameter of the particles for which $10 \%$ of the particles are finer and $90 \%$ of the particles are coarser than that $D_{10}$.

There are some limitations for coarser and finer fractions of natural adsorbents. For the coarser fraction $(>0.6$ $\mathrm{mm}$ ), as the particle size increases, specific surface area decreases, which results in inefficient adsorption. For the finer fraction, $(<0.425 \mathrm{~mm})$ from the Figure 2 , it is evident that the percentage of fineness is very less (approximately less than 30\%). Therefore, the fraction of adsorbent under the required size will be less, which in turn needs to be ground, resulting in an increase in the preparation cost of adsorbent (Kumar \& Bandyopadhyay, 2006). Hence, natural adsorbents of size ranging between $0.6 \mathrm{~mm}-0.425$ $\mathrm{mm}$ have been selected for the experimental works in this study. From Figure 2, it was found that the percentage of fineness of $\mathrm{RH}, \mathrm{SD}$ and $\mathrm{CD}$ in size range $0.6 \mathrm{~mm}-0.425$ $\mathrm{mm}$ was less by $37.2 \%, 60 \%$ and $39.27 \%$ respectively when compared with percentage of fineness of coarser fraction of sizes ranging between $4.75 \mathrm{~mm}-2.36 \mathrm{~mm}$. Further, it was greater by $90.3 \%, 96 \%$ and $97.3 \%$ when compared with percentage of fineness of finer fraction of $\mathrm{RH}, \mathrm{SD}$ and $\mathrm{CD}$ in size range $<0.075$ respectively. The percentage

Table 2. Particle size distribution of RH, SD, CD

\begin{tabular}{|c|l|c|c|c|c|c|c|c|c|c|}
\hline \multirow{2}{*}{ S. No. } & \multirow{2}{*}{$\begin{array}{c}\text { Adsorbent } \\
\text { (\% Fineness) }\end{array}$} & \multicolumn{9}{|c|}{ Size distribution (mm) } \\
\cline { 3 - 13 } & & $4.75-2.36$ & $2.36-2$ & $2-1.18$ & $1.18-0.6$ & $0.6-0.425$ & $0.425-0.300$ & $0.300-0.150$ & $0.150-0.075$ & $0.075-$ PAN \\
\hline 1. & Rice husk(\%) & 98.4 & 97.0 & 95.8 & 86.8 & 61.8 & 32.4 & 24.0 & 8.0 & 6.0 \\
\hline 2. & Saw dust(\%) & 100.0 & 100.0 & 99.0 & 62.0 & 40.0 & 26.0 & 18.0 & 5.6 & 1.6 \\
\hline 3. & Coir dust(\%) & 98.8 & 97.2 & 94.4 & 80.8 & 60.0 & 41.2 & 28.4 & 4.4 & 1.6 \\
\hline
\end{tabular}

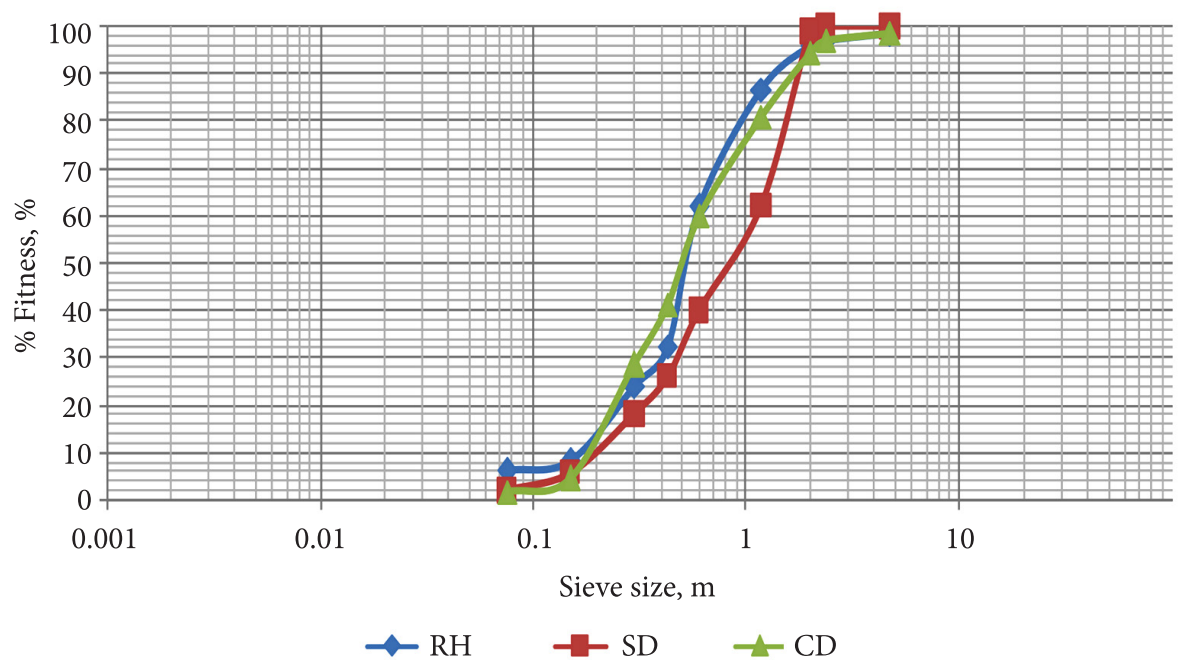

Figure 2. Size distribution curve of natural adsorbents 
of fineness for fraction of adsorbent whose size $>0.6 \mathrm{~mm}$ was found to be ranging between $62 \%$ and $100 \%$, and the same parameter for the fraction of adsorbent in the size $<0.425 \mathrm{~mm}$ was $1.6 \%$ and $41.2 \%$. Having chosen adsorbent sizes ranging between $0.425 \mathrm{~mm}$ and $0.6 \mathrm{~mm}$, it can be construed that percentage of fineness approximately 40 to $60 \%$ is suitable when natural adsorbent is chosen for chromium removal. The average percentage of fineness in the size range between $0.6 \mathrm{~mm}$ and $0.425 \mathrm{~mm}$ was found to be $54 \%$. In otherwords, if natural adsorbent is used to remove heavy metal, a percentage of fineness around 54\% could be used for better removal.

\subsection{Characterization of adsorbents}

Samples of Rice Husk (RH), Saw Dust (SD) and Coir Dust (CD) were analysed using Energy Dispersive X-Ray Spectroscopy (EDX). An EDX system called Quanta FEG 250 Analysis Station was used to determine the chemical elemental composition. The EDX pattern of rice husk (RH), Saw Dust (SD) and Coir Dust (CD) sample is shown in Figure $3 \mathrm{a}, \mathrm{b}$ and $\mathrm{c}$ respectively and the chemical composition of rice husk, Saw dust and Coir dust in terms of atomic weight (\%) and weight (\%) is tabulated next to EDX pattern.

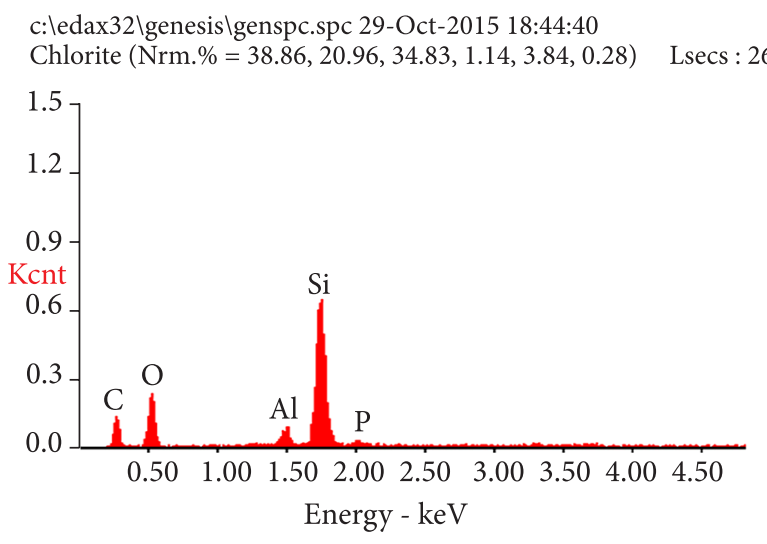

\begin{tabular}{|c|c|c|}
\hline Element & Wt \% & At \% \\
\hline $\mathrm{C} \mathrm{K}$ & 43.01 & 54.75 \\
\hline $\mathrm{O} \mathrm{K}$ & 34.56 & 33.03 \\
\hline $\mathrm{Al} \mathrm{K}$ & 02.50 & 01.42 \\
\hline $\mathrm{Si} \mathrm{K}$ & 18.92 & 10.30 \\
\hline $\mathrm{P} \mathrm{K}$ & 01.01 & 00.50 \\
\hline
\end{tabular}

a) Rice Husk (RH)

c:ledax32 Igenesis/genspc.spc 29-Oct-2015 18:49:38 Chlorite (Nrm.\% $=38.86,20.96,34.83,1.14,3.84,0.28) \quad$ Lsecs : 28

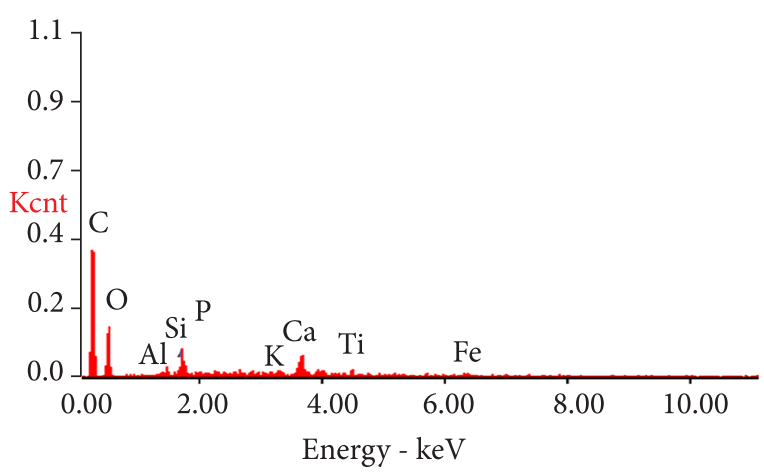

\begin{tabular}{|c|c|c|}
\hline Element & Wt \% & At \% \\
\hline C K & 63.21 & 71.21 \\
\hline O K & 31.71 & 26.82 \\
\hline Al K & 00.57 & 00.28 \\
\hline Si K & 01.64 & 00.79 \\
\hline P K & 00.06 & 00.03 \\
\hline K K & 00.24 & 00.08 \\
\hline Ca K & 01.53 & 00.52 \\
\hline Ti K & 00.43 & 00.12 \\
\hline Fe K & 00.63 & 00.15 \\
\hline
\end{tabular}

b) Saw Dust (SD)

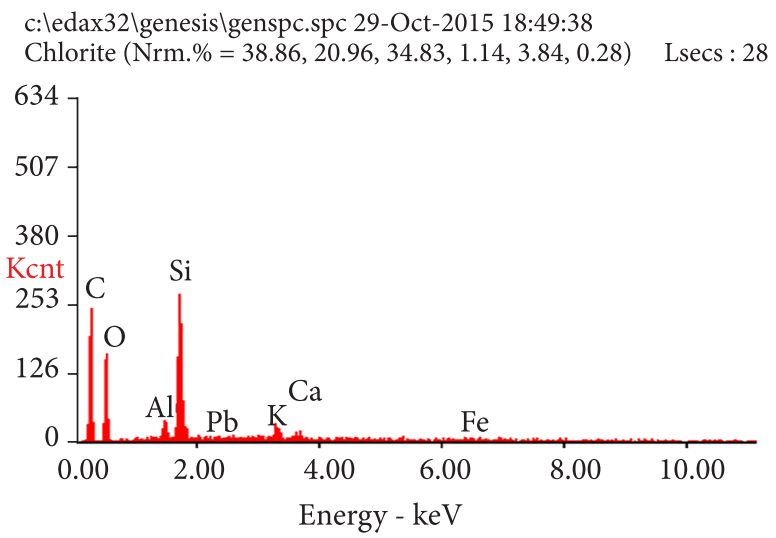

\begin{tabular}{|c|c|c|}
\hline Element & Wt \% & At \% \\
\hline $\mathrm{C} \mathrm{K}$ & 57.29 & 67.12 \\
\hline $\mathrm{O} \mathrm{K}$ & 31.50 & 27.71 \\
\hline $\mathrm{AlK}$ & 01.14 & 00.60 \\
\hline $\mathrm{SiK}$ & 07.92 & 03.97 \\
\hline $\mathrm{PbM}$ & 00.27 & 00.02 \\
\hline $\mathrm{K} \mathrm{K}$ & 00.77 & 00.28 \\
\hline $\mathrm{CaK}$ & 00.40 & 00.14 \\
\hline $\mathrm{FeK}$ & 00.70 & 00.18 \\
\hline
\end{tabular}

c) Coir Dust (CD)

Figure 3. EDX Pattern along with chemical composition of a) RH; b) SD; c) CD 
From the Figure 3a, it is clear that rice husk contains 43.01\% Carbon; 34.56\% Oxygen and 18.92\% Silica by weight, these were confirmed as major components in the EDX pattern. It also contains $2.50 \%$ aluminium and $1.01 \%$ potassium by weight which is considered as minor constituents. In a study by Rahman, Ismail and Osman (1997), it was observed that rice husk consists of cellulose (32.24\%), hemicellulose $(21.34 \%)$, lignin $(21.44 \%)$ and mineral ash $(15.05 \%)$ as well as high percentage of silica in its mineral ash, which is approximately $96.34 \%$ which resulted in overall percentage of silica of $14.5 \%$. In the present study, percentage of silica was found to be $18.92 \%$. From the previous studies, it was well proved that silica was efficient in removing heavy metal. Additionally, rice husk possesses properties like good chemical stability, high mechanical strength, insolubility in water, and also possesses a granular structure, which makes it a good adsorbent material for removing heavy metals from wastewater (Wan Ngah \& Hanafiah, 2008). Excluding carbon and oxygen, the other element present in high percentages in the three natural adsorbents was silica, which has positive charges indicating its cation exchange capacity to replace $\mathrm{Cr}(\mathrm{VI})$ ions.

Saw Dust (SD) sample contains $63.21 \%$ carbon, $31.71 \%$ oxygen, $1.64 \%$ silica and $1.53 \%$ calcium, which are confirmed to be major components by the definite peak heights seen in the EDX pattern of SD sample in Figure 3b. Coir Dust sample contains carbon, oxygen, silica and aluminium as major constituents with $57.29 \%$, 30.50\%, $7.92 \%$ and $1.14 \%$ by weight respectively. Moreover in a study by S. Q. Memon, N. Memon, Shah, Khuhawar, and Bhanger (2007) that conducts proximate analysis for sawdust, it was found that the cell wall of sawdust mainly consists of acid detergent fiber (containing cellulose and lignin), crude fiber, and many hydroxyl groups such as tenins and other phenolic compounds. All those are active ion exchange compounds that could bind heavy metal ions through different mechanisms (Shukla et al., 2002).

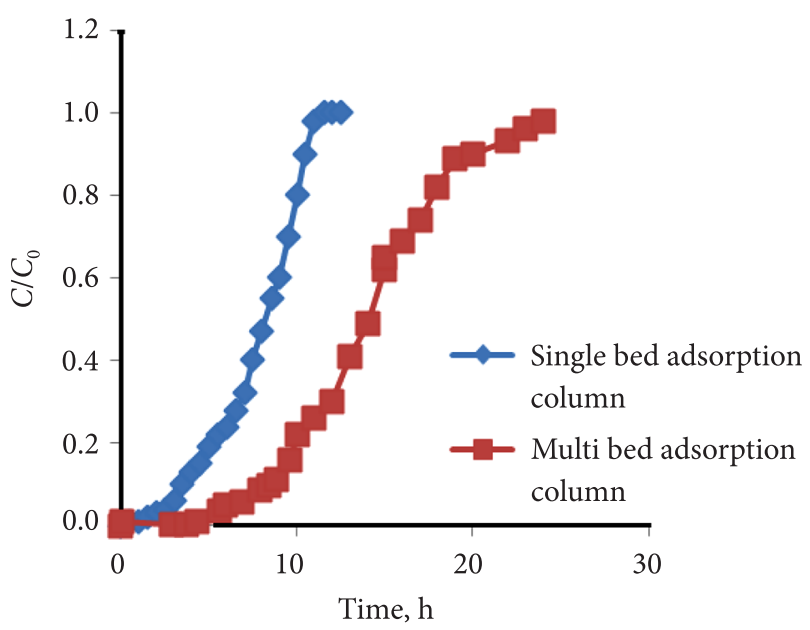

Figure 4. Comparison of experimental breakthrough curves of single bed adsorption column and multi bed adsorption column (Initial Concentration of Cr(VI) $=200 \mathrm{mg} / \mathrm{L}$, flow rate $=9.5 \mathrm{~mL} / \mathrm{min}$, temperature $25^{\circ} \mathrm{C}$ )
EDX pattern of coir dust (CD) sample confirms the same with distinct peaks in Figure $3 \mathrm{c}$. Potassium, Ferrous, Calcium and lead were found to be the minor constituents of CD with $0.77 \%, 0.70 \%, 0.40 \%, 0.27 \%$ by weight respectively. A study by Ajmal et al. (2003) suggests that the constituents of coir dust include lignin $-36.15 \%$, cellulose $-33.61 \%$, pentosana $-29.27 \%$, ash $-0.61 \%$, dry basis. The other constituents are kemi celluloses and extractives. Pectins with polyphenolic, tannins, hydroxyl and carboxyl groups are present in these extractives. Adsorptive/ion exchange properties are contributed by cellulose and lignin present in coir. The porous structure of the coir dust helps in adsorption of large amount of water but nevertheless, remain insoluble very much like any synthetic hydrogel (Bishnoi et al., 2004).

\subsection{Comparison of single bed and multi bed adsorption column}

In the present column studies, the operational conditions such as initial $\mathrm{Cr}(\mathrm{VI})$ concentration $(200 \mathrm{mg} / \mathrm{L})$, flow rate (9.5 mL/min), adsorbent size $0.6 \mathrm{~mm}-0.425 \mathrm{~mm}$, column diameter $(3 \mathrm{~cm})$ and bed depth $(30 \mathrm{~cm})$ remains the same for both single layer adsorption column and multi layer adsorption column. Only variation is that, in multi layer adsorption column CD, SD and RH were filled as separate layers each of $10 \mathrm{~cm}$ depth altogether making $30 \mathrm{~cm}$ bed depth whereas, in single layer as the name denotes single adsorbent i.e., $\mathrm{RH}$ alone is filled as adsorbent creating a bed depth of $30 \mathrm{~cm}$ as shown in Figure 1a. The main purpose of this study is to compare the performance of single and multilayer adsorption column, for which key parameters like breakthrough time, porosity and specific surface area of the adsorbents are studied.

The concept of the breakthrough curve is used to describe the performance of packed beds. The shape of the breakthrough curve and the time taken for breakthrough appearance are the important characteristics for determining the operation and the response of a adsorption column. From the column, experimental results for single bed and multi bed, trial run breakthrough curves were plotted between $C / C_{0}$ Vs. Time " $t$ " in hours and is shown in Figure 4. From the Figure 4, it is observed that in single layer adsorption studies the time taken to achieve breakthrough (effluent concentration reaches $10 \%$ of influent concentration) was 3.44 hours and the bed was found to be exhausted (effluent concentration is $90 \%$ of influent concentration) at 10.5 hours. In multi layer adsorption the breakthrough time and exhaustion point is 8.8 hours and 20 hours respectively. From the breakthrough curve for single bed and multi bed column studies, it is evident that the multi bed adsorption column performs better as the time taken to achieve breakthrough in multi bed column is 2.5 times greater and exhaustion time is 1.9 times greater than the time taken by single bed adsorption studies respectively. From the shape of the breakthrough curve, it is observed that the slope of multi bed adsorption column breakthrough curve is less steep when compared to the 
slope of the single bed adsorption column. This results in broadened mass transfer zone (MTZ) which may be due to the influence of physical properties like porosity and specific surface area of adsorbent present in multi layer adsorption column.

In general, when the adsorbent is less porous, volume of voids will be less, which results in a larger specific surface area which makes more active sites available for adsorption, eventually increasing removal efficiency (Han et al., 2009). The adsorption capacity of the adsorbent " $q$ " for single and multi bed adsorption column were calculated for volume of metal effluent treated up to breakthrough and given in Table 3. From the previous literatures studied, the porosity and specific surface area of rice husk, saw dust and coir dust were found to be $85.28 \% \& 1.4 \mathrm{~m}^{2} / \mathrm{g}$; $90 \% \& 0.72 \mathrm{~m}^{2} / \mathrm{g}$ and $96.26 \% \& 0.68 \mathrm{~m}^{2} / \mathrm{g}$ respectively (Razi, Khanif, Shaharuddin, \& Marziah, 2004; Bulut \& Tez, 2007; Vieira, de Almeida Neto, Carlos da Silva, Nóbrega, \& Melo Filho, 2012; Shukla et al., 2002). From the Table 4, it is clear that adsorbent (RH) with porosity of $85.28 \%$ has greater surface area of $1.4 \mathrm{~m}^{2} / \mathrm{g}$ and greater adsorption capacity of about $173.91 \mathrm{mg} / \mathrm{g}$ in multi bed adsorption column and the same adsorbent with same specific surface area and porosity provides an adsorption capacity of $20.06 \mathrm{mg} / \mathrm{g}$ in single bed adsorption column. This proves that the use of multilayer adsorbent system would improve the performance of the column and extend the life of the adsorbent with greater removal efficiency.

\subsection{Analytical column studies}

Lab scale column study is done to obtain data from experimental breakthrough curve which is required for design of column adsorption process. The experimental data is to be verified by kinetic models for the prediction of concentration-time profile at varying initial conditions. Kinetic models like Thomas model and Yoon-Nelson model were used to analytically verify the experimental breakthrough curve of column studies. BDST model was used to predict the critical bed depth $\left(\mathrm{X}_{0}\right)$ and the parameters necessary for column design. From the Figure 5a, the breakthrough curve of single bed adsorption column was obtained by plotting $\mathrm{C} / \mathrm{C}_{0}$ against time " $t$ " in hours for both modelled and experimental data that has a flow rate of $9.5 \mathrm{~mL} / \mathrm{min}$, an initial $\mathrm{Cr}(\mathrm{VI})$ concentration of $200 \mathrm{mg} / \mathrm{L}$ and rice husk as adsorbent for a bed depth of $30 \mathrm{~cm}$. For multi bed adsorption column breakthrough curve was plotted for each bed between $\mathrm{C} / \mathrm{C}_{0}$ and time " $t$ " in hours for both experimental and modelled data with the similar testing conditions, with the only difference being the usage of three adsorbents, each contributing $10 \mathrm{~cm}$ depth amounting to a total bed depth of $30 \mathrm{~cm}$. The modelled and experimental breakthrough curve plotted for multi bed adsorption column is shown in Figure 5b.

BDST approach is actually based on Bohart and Adams equation, which governs surface reaction rate theory. The one of the important parameters used in this approach is Critical bed depth $\left(\mathrm{X}_{0}\right)$ that is nothing but minimum bed depth required to obtain the desired effluent quality. However, over a period of time, it is expected that adsorbent saturates with influent components especially with heavy metal. In this regard, at what time saturation of bed attained, is the important factor to be investigated. Here, with the help of slope of BDST line, it allows us to evaluate time required for the adsorption zone to travel a unit length through the adsorbent. Furthermore, if this zone extends to its full depth, it connotes time for regeneration/ replacement of adsorbent.

Thomas model is applicable in system with a constant flow rate and no axial dispersion. With the given flow rate of $9.5 \mathrm{~mL} / \mathrm{min}$, it could be assumed that axial dispersion doesn't take place. Hence, it is quite logical to surmise that Thomas model would fit better with experimental data.

The Yoon-Nelson model is a descriptive model that uses experimental data to calculate parameters that are then entered into the model. The basic equation for the

Table 3. Adsorption capacity of adsorbent required up to breakthrough for single bed adsorption and multi bed adsorption column study with initial concentration as $200 \mathrm{mg} / \mathrm{L}$

\begin{tabular}{|c|c|c|c|c|c|c|}
\hline $\begin{array}{c}\text { Trial } \\
\text { run }\end{array}$ & $\begin{array}{c}\text { Bed depth } \\
(\mathrm{cm})\end{array}$ & $\begin{array}{c}\text { 10\% breakthrough } \\
\text { time (Hr) }\end{array}$ & $\begin{array}{c}\text { Treated } \\
\text { volume }(\mathrm{L})\end{array}$ & $\begin{array}{c}\text { Total mass of } \\
\text { adsorbent }(\mathrm{g})\end{array}$ & $\begin{array}{c}\text { Mass of adsorbent/litre of } \\
\text { treated effluent }(\mathrm{g} / \mathrm{L})\end{array}$ & $\begin{array}{c}\text { Adsorption capa- } \\
\text { city “ } q \text { ” }(\mathrm{mg} / \mathrm{g})\end{array}$ \\
\hline \multirow{3}{*}{ Multi bed } & 10 & 1.3 & 0.7 & 9.2 & 12.4 & 16.1 \\
\cline { 2 - 7 } & 20 & 6.3 & 3.6 & 10.2 & 2.8 & 70.9 \\
\cline { 2 - 7 } & 30 & 9.2 & 5.2 & 6.0 & 1.2 & 173.9 \\
\hline Single bed & 30 & 3.4 & 1.9 & 19.2 & 10.0 & 20.1 \\
\hline
\end{tabular}

Table 4. Parameters for comparison of single bed and multi bed adsorption column on $\mathrm{Cr}(\mathrm{VI})$ adsorption

\begin{tabular}{|c|c|c|c|l|}
\hline Sl. No. & Adsorbent & Specific surface area $\left(\mathrm{m}^{2} / \mathrm{g}\right)$ & Porosity (\%) & \multicolumn{1}{|c|}{ References } \\
\hline 1. & CD & 0.68 & 96.26 & $\begin{array}{l}\text { Jeyaseeli and Ray (2010) } \\
\text { Asiah et al. (2004) }\end{array}$ \\
\hline 2. & SD & 0.72 & 90.00 & Bulut and Tez (2007) \\
\hline 3. & RH & 1.40 & 85.28 & $\begin{array}{l}\text { Vieira et al. (2012) } \\
\text { Zhang et al. (2012) }\end{array}$ \\
\hline
\end{tabular}




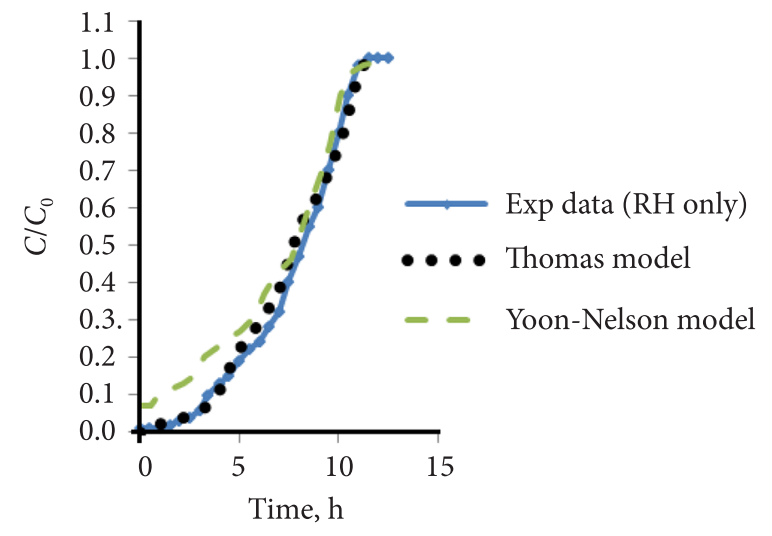

a) Breakthrough curves for single bed adsorption column with $\mathrm{RH}$ as adsorbent (bed depth $=30 \mathrm{~cm}$; initial concentration $=$ $200 \mathrm{mg} / \mathrm{L}$; temperature $=25^{\circ} \mathrm{C}$ )

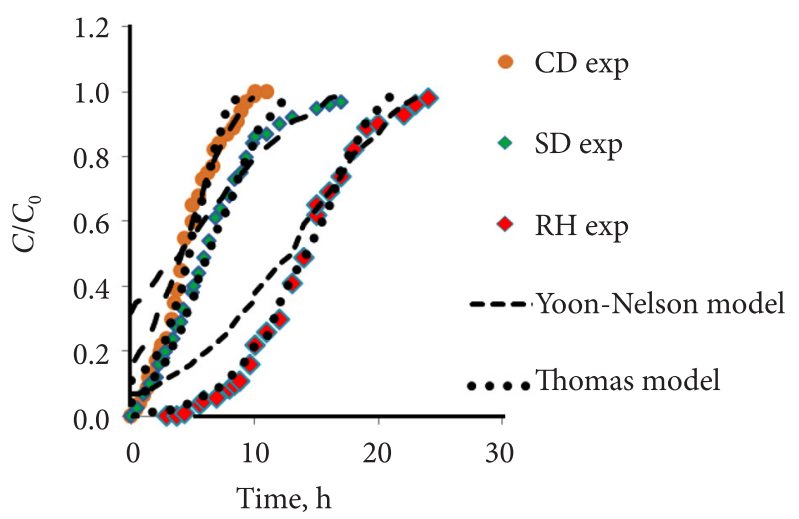

b) Breakthrough curves for multi-bed adsorption column with $\mathrm{RH}, \mathrm{SD}$ and $\mathrm{CD}$ as adsorbent (bed depth $=30 \mathrm{~cm}$; initial concentration $=200 \mathrm{mg} / \mathrm{L}$; temperature $=25^{\circ} \mathrm{C}$ )

Figure 5. Comparison of the experimental \& predicted breakthrough curves obtained according to The Thomas model and YoonNelson model for a) single bed adsorption column and b) multi bed adsorption column

model is already given in the section 2.5.3. To determine the constants involved in this model requires minimum of three experimental data. However, inclusion of more data points further strengths accuracy of the model

\subsubsection{Application of BDST model}

The BDST correlation was developed by plotting the data of breakthrough curve for each bed depth of 10,20 and $30 \mathrm{~cm}$ in multi bed adsorption system against the time taken to reach $10 \%$ breakthrough and $90 \%$ breakthrough of $\mathrm{Cr}(\mathrm{VI})$ removal $\left(C / C_{0}=0.1\right.$ and $\left.C / C_{0}=0.9\right)$ at each bed depth as shown in Figure 6. The slope and intercept of the $10 \%$ saturation line in Figure 6 is taken to find the design parameters like adsorption rate constant " $k_{a d s}$ " and adsorption capacity " $N_{0}$ " respectively. Critical bed depth $\left(X_{0}\right)$ required to maintain the desired effluent concentration $\left(C_{b}\right)$ was calculated using Eq. (6). The obtained values of $k_{a d s}, N_{0}$ and $X_{0}$ were $0.123 \mathrm{~L} / \mathrm{mg} \mathrm{h}, 474.36 \mathrm{mg} / \mathrm{L}$, $1.37 \mathrm{~cm}$, respectively. BDST model predicts performance of multibed in terms of service time at breakthrough point. Service time is a function of inlet concentration of heavy metal, breakthrough concentration of heavy metal,

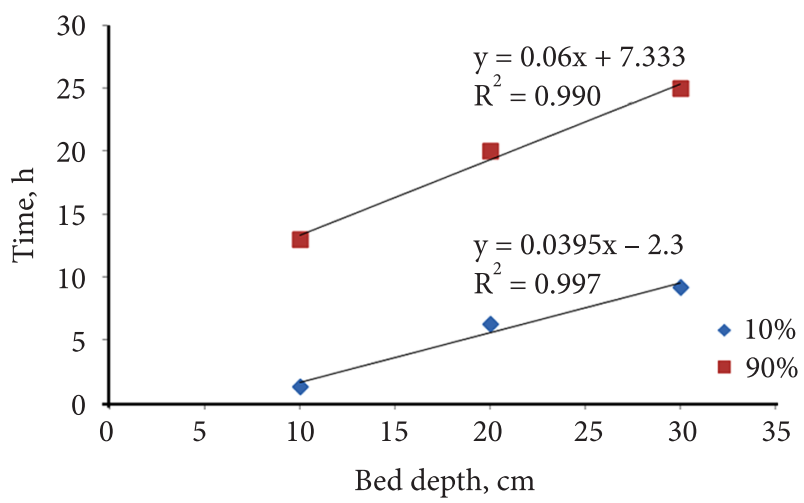

Figure 6. BDST Plot for multi bed adsorption column on $\mathrm{Cr}(\mathrm{VI})$ adsorption with initial concentration as $200 \mathrm{mg} / \mathrm{L}$ flow rate, cross section area of bed and so on. For future studies having had all those parameters (which need not be performed experimentally at laboratory, but can be of assumed values) one can predict service time of given bed by fitting them into the model. In short, Scale up of the process for other flow rates can be done through BDST model without any further experimental runs. From the Figure 6, value of $R^{2}=0.997$ which proves that the suitability of BDST model for multi bed adsorption column holds good.

\subsubsection{Application of Thomas model}

The kinetic data was fitted using Thomas model for the three different adsorbents of multi bed adsorption system and to the single adsorbent of single bed adsorption system at constant flow rate of $9.5 \mathrm{~mL} / \mathrm{min}$, initial $\mathrm{Cr}(\mathrm{VI})$ concentration of $200 \mathrm{mg} / \mathrm{L}$, and a bed depth of $30 \mathrm{~cm}$. From the slope and intercept of the plot, the Thomas rate constant $\left(k_{T H}\right)$ and bed capacity $\left(q_{0}\right)$ can be determined respectively. The graphs plotted between $\ln \left(C_{0} / C-1\right)$ and time " $t$ " in minutes for both single bed adsorption column and multi bed adsorption column are shown in Figure 7a and Figure $7 \mathrm{~b}$ respectively.

The regression coefficient $\left(R^{2}\right)$ and relative constants were calculated by regression analysis. The calculated values of $k_{T H}, q_{0}, \mathrm{R}^{2}$ and values of sum of squares error (SS) were provided in the Table 5, where the values of $\mathrm{R}^{2}$ ranges from 0.954 to 0.997 for multi bed adsorption column, and for single bed adsorption column $\mathrm{R}^{2}$ was 0.975 . From the Table 5, it can be observed that in multi bed adsorption column, as the depth of liquid flowing through multilayer adsorbent media increases from the top in multi bed adsorption column, the value of $k_{T H}$ was found to decrease while the value of $q_{0}$ was found to increase. The reason behind this is that, as the depth of liquid flowing through multilayer adsorbent media increases, the contact time of $\mathrm{Cr}(\mathrm{VI})$ with the different adsorbents in multi layer 


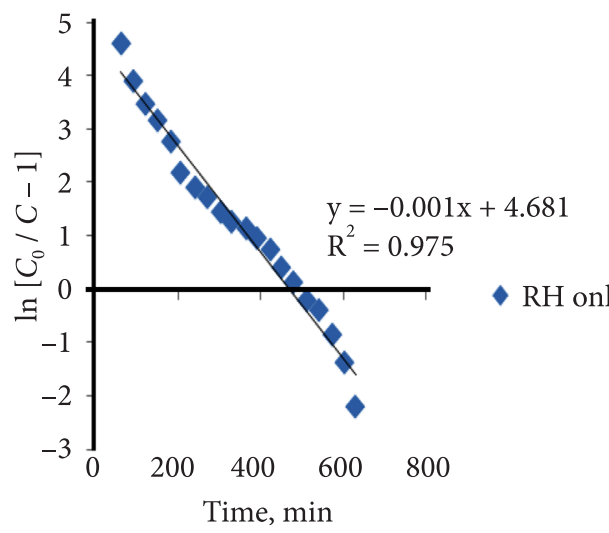

a) Thomas model plot of single bed adsorption column

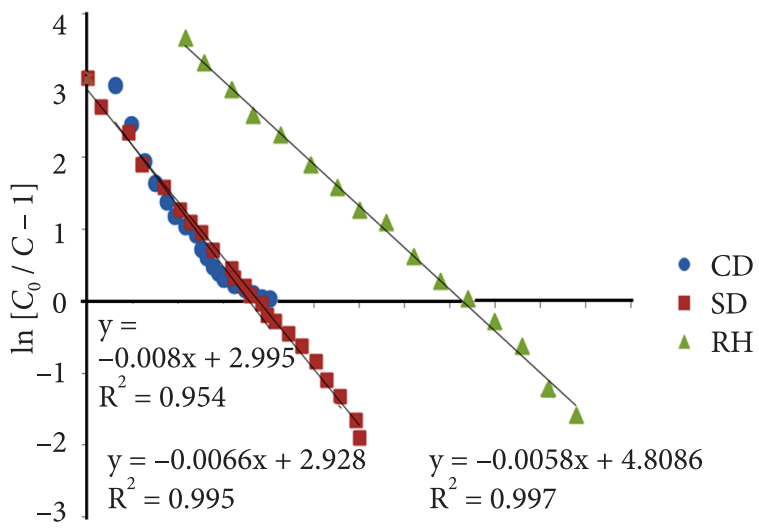

0100200300400500600700800900100011001200

Time, $\min$

b) Thomas model plot of multi bed adsorption column

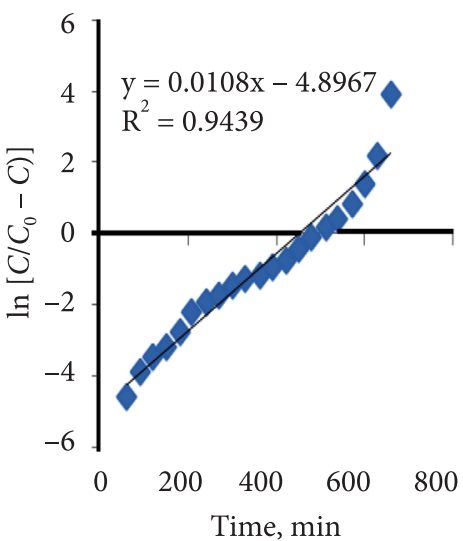

c) Yoon-Nelson model plot of single bed adsorption column

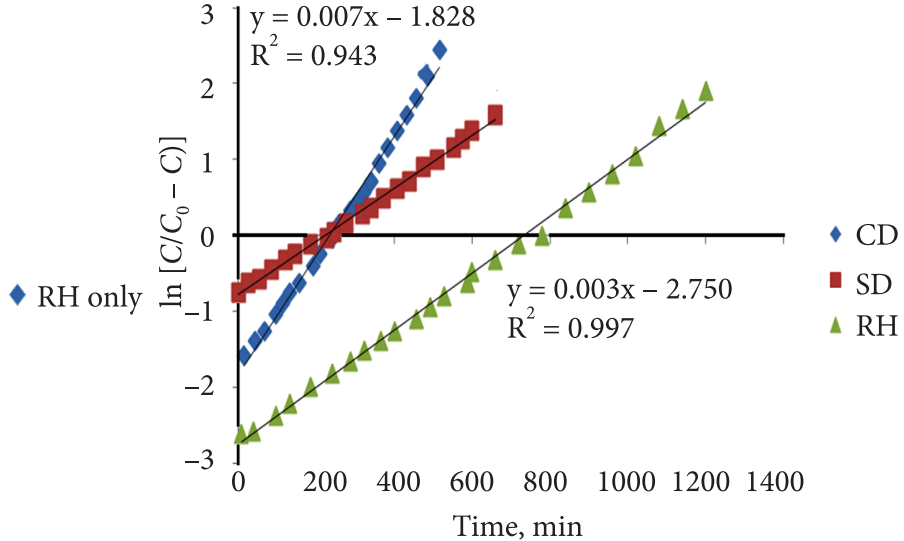

d) Yoon-Nelson model plot of multi bed adsorption column

Figure 7. Thomas model and Yoon-Nelson model plots of single bed adsorption column and multi bed adsorption column with initial concentration as $200 \mathrm{mg} / \mathrm{L}$

Table 5. Parameters predicted from Thomas model using regression analysis for single bed and multi bed adsorption column on $\mathrm{Cr}(\mathrm{VI})$ adsorption $\left(\mathrm{C}_{0}=200 \mathrm{mg} / \mathrm{L}, \mathrm{v}=9.5 \mathrm{~mL} / \mathrm{min}^{-1}\right)$

\begin{tabular}{|c|c|c|c|c|c|c|c|}
\hline \multirow{2}{*}{ S. No. } & \multirow{2}{*}{ Trial run } & \multirow{2}{*}{ Adsorbent } & \multirow{2}{*}{ Bed depth $(\mathrm{cm})$} & \multicolumn{2}{|c|}{ Thomas model parameters } & \multirow{2}{*}{$\mathrm{R}^{2}$} & \multirow{2}{*}{ SS } \\
\hline & & & & $k_{T H}\left(\mathrm{~L} \mathrm{~min}^{-1} \mathrm{mg}^{-1}\right)$ & $q_{0}(\mathrm{mg} / \mathrm{g})$ & & \\
\hline \multirow{3}{*}{1.} & \multirow{3}{*}{ Multi bed } & $\mathrm{CD}$ & 0 to 10 & $3.5 \times 10^{-5}$ & 75.28 & 0.954 & 0.265 \\
\hline & & SD & 10 to 20 & $3.3 \times 10^{-5}$ & 83.05 & 0.995 & 0.120 \\
\hline & & $\mathrm{RH}$ & 20 to 30 & $3 \times 10^{-5}$ & 263.8 & 0.997 & 0.255 \\
\hline 2. & Single bed & $\mathrm{RH}$ & 30 & $5 \times 10^{-5}$ & 204.26 & 0.975 & 0.179 \\
\hline
\end{tabular}

column is increased which resulted in higher removal capacity of adsorbent. Moreover, high adsorption capacity was noted at bottom most layer of the bed which was filled with RH. Furthermore, it can be substantiated, that the specific surface area of $\mathrm{RH}$ was found to be greater when compared with other adsorbents, thereby providing more binding sites.

The modelled breakthrough curve can be obtained by fitting the calculated data of single bed and multi bed adsorption column in Thomas model Eq. (8) and is plotted as shown in Figure $7 \mathrm{a}$ and Figure $7 \mathrm{~b}$ respectively. From the plot of breakthrough curves of both single and multi bed adsorption column, it is clear that the experimental curve and predicted curve are in a good agreement. In addition to that, higher $\mathrm{R}^{2}$ value and smaller SS value proves that Thomas model is suitable to explain the adsorption of $\mathrm{Cr}(\mathrm{VI})$ in single and multi bed adsorption column of natural adsorbents and the parameters obtained can be used for the design of the column. 
Table 6. Parameters predicted from Yoon-Nelson model for single bed and multi bed adsorption column on Cr(VI) adsorption $\left(\mathrm{C}_{0}=200 \mathrm{mg} / \mathrm{L}, \mathrm{v}=9.5 \mathrm{~mL} / \mathrm{min}^{-1}\right)$

\begin{tabular}{|c|c|c|c|c|c|c|c|}
\hline \multirow{2}{*}{ S. No. } & \multirow{2}{*}{ Trial run } & \multirow{2}{*}{ Adsorbent } & \multirow{2}{*}{ Bed depth $(\mathrm{cm})$} & \multicolumn{2}{|c|}{ Yoon-Nelson model parameters } & \multirow{2}{*}{$\mathrm{R}^{2}$} & \multirow{2}{*}{ SS } \\
\hline & & & & $k_{Y N}\left(\mathrm{~L} \min ^{-1}\right)$ & $t(\min )$ & & \\
\hline \multirow{3}{*}{1.} & \multirow{3}{*}{ Multi bed } & $\mathrm{CD}$ & 0 to 10 & 0.007 & 261.14 & 0.943 & 1.07 \\
\hline & & SD & 10 to 20 & 0.003 & 275.05 & 0.996 & 3.50 \\
\hline & & $\mathrm{RH}$ & 20 to 30 & 0.003 & 916.66 & 0.997 & 1.40 \\
\hline 2. & Single bed & $\mathrm{RH}$ & 30 & 0.001 & 489.6 & 0.943 & 0.93 \\
\hline
\end{tabular}

\subsubsection{Application of Yoon-Nelson model}

Yoon-Nelson developed a simple theoretical model in 1984, which is now applied to study the breakthrough behaviour of $\mathrm{Cr}(\mathrm{VI})$ in single and multi bed adsorption column of natural adsorbents. The value of unknown parameters of Yoon-Nelson model i.e., $k_{Y N}$ (Yoon-Nelson rate constant) and $t$ (the time required for $50 \% \mathrm{Cr}(\mathrm{VI})$ breakthrough) could be calculated from the slope and intercept of the plot between $\ln \left[\mathrm{C} /\left(\mathrm{C}_{0}-\mathrm{C}\right)\right]$ and time " $t$ " in minutes for both single and multi bed adsorption column as shown in Figure $7 \mathrm{c}$ and Figure $7 \mathrm{~d}$ respectively.

The parameters of Yoon-Nelson model were given in Table 6 along with the values of $\mathrm{R}^{2}$ and SS obtained by regression analysis. From the Table 6, it is clear that as depth of the bed increases in multi bed adsorption column, $\mathrm{t}$ value also increases while value of $\mathrm{k}_{\mathrm{YN}}$ decreases. The value of $\mathrm{t}$ in Table 6 coincides with the experimental value as in Figure 5, except for the Sawdust adsorbent layer in multi bed adsorption column. The predicted curve according to Yoon-Nelson model is plotted along with experimental curve for both single and multi bed adsorption column in Figure $7 \mathrm{c}$ and Figure $7 \mathrm{~d}$ respectively. From Table 6, it is observed that the SS value is greater for Yoon-Nelson model when compared to Thomas model. Hence experimental breakthrough curves were not fitting to those breakthrough curves predicted by Yoon-Nelson model as compared to Thomas model.

\subsection{Cost comparison of natural adsorbents with activated carbon}

The driving factor for the present research work undergone to find an alternative adsorbent to activated carbon is its high cost. Hence, the cost of natural adsorbents used in this study is compared with the market cost of activated carbon. Market cost of activated carbon is around USD $2 / \mathrm{kg}$ whereas the costs $/ \mathrm{kg}$ of natural adsorbents CD, SD and RH are USD 0.10, USD 0.05 and USD 0.06respectively. Further, the cost $/ \mathrm{kg}$ of adsorbent for treated volume of metal effluent up to $10 \%$ breakpoint is calculated, for which the mass of adsorbent required up to breakthrough is needed. Thus the necessary data was calculated using experimental data and are given in Table 3. From the Table 3, it is clear that for single bed adsorption column the mass of adsorbent required to achieve breakthrough is high. From Table 7, for multi bed adsorption column, the average of volume of treated effluent $/ \mathrm{kg}$ of adsorbent was found to be $435 \mathrm{~L}$ and the average cost $/ \mathrm{kg}$ of all three adsorbents were found to be USD 0.07. Thus in multi bed adsorption column, the volume of effluent treated/USD is around $7455 \mathrm{~L} / \mathrm{USD}$. But in single bed adsorption column, the volume of effluent treated/USD is around 1596 L/USD. Thus multi bed adsorption column is proven to be economical.

In a developing country like India a typical steel industry generates effluent of 25000 to 30000 litres approximately for processing of iron ore to finished steel products (SAIL, Tamil Nadu, India). Assuming that approximately $10 \%$ of the effluent volume gets reduced as sludge during treatment process, the remaining 31500 litres (90\% of effluent) leaves the treatment plant. In this study, $60 \mathrm{~L}$ of influent was taken and treated by using both single bed and multi bed adsorption column. From Table 3, the volume of effluent treated up to $10 \%$ breakthrough in multi bed adsorption column was found to be $5.24 \mathrm{~L}$ which is equal to $8.73 \%$ of influent taken. In single bed adsorption column the volume of effluent treated up to $10 \%$ breakthrough was found to be $1.93 \mathrm{~L}$ which is equal to $3.21 \%$ of influent taken. Thus for treatment of $27000 \mathrm{~L}$ of steel industrial effluent using single bed adsorption column using Rice husk as adsorbent, the treated volume of effluent at $10 \%$ breakthrough would be approximately $3.21 \%$ of influent i.e., 870 L. For treatment of same volume of steel industrial effluent using multi bed adsorption column

Table 7. Cost for treated volume of metal effluent up to breakthrough/kg of adsorbent

\begin{tabular}{|c|c|c|c|c|}
\hline \multirow{2}{*}{ Trial run } & Adsorbent & $\begin{array}{c}\text { Volume (L) of effluent } \\
\text { treated/kg of adsorbent }\end{array}$ & $\begin{array}{c}\text { Cost per kg of adsorbent } \\
\text { (USD/kg) }\end{array}$ & $\begin{array}{c}\text { Volume of effluent treated up to } \\
\text { breakthroug/One US Dollar (L/USD) }\end{array}$ \\
\hline \multirow{3}{*}{ Multi bed } & CD & 80 & 0.10 & 800 \\
\cline { 2 - 5 } & SD & 354 & 0.05 & 7080 \\
\cline { 2 - 5 } & RH & 869 & 0.06 & 14483 \\
\hline Single bed & RH & 100 & 0.06 & 1667 \\
\hline
\end{tabular}


using $\mathrm{CD}, \mathrm{SD}$ and $\mathrm{RH}$ as adsorbent, the treated volume of effluent at $10 \%$ breakthrough would be approximately $8.73 \%$ of influent taken i.e., $2357 \mathrm{~L}$. Thus the volume of effluent treated up to breakthrough/rupee for single bed adsorption column and multi bed adsorption column would be $222128 \mathrm{~L} /$ USD and $32681 \mathrm{~L} /$ USD respectively. For one rupee, multi bed adsorption column is 6.8 times more economical in treating effluent when compared to single bed adsorption column under same working conditions.

\section{Conclusions}

The present investigation confirms that the locally, abundantly available agricultural wastes viz. Rice husk (RH), Sawdust (SD) and Coir dust (CD) could be used as an alternative to commercially available activated carbon for the removal of $\mathrm{Cr}(\mathrm{VI})$ from synthetic wastewater. The characterisation of natural adsorbents viz. rice husk, saw dust and coir dust indicate the presence of carbon, aluminium and silica as major components and hence adsorbents were used without any activation process in the present study and thus minimizing the preparation cost of adsorbent. For natural adsorbents percentage of fineness around $54 \%$ could be used for better heavy metal removal.

From the study on performance of single bed and multi bed adsorption column on removal of heavy metal $\mathrm{Cr}(\mathrm{VI})$ from synthetic wastewater, following conclusions are made:

From the breakthrough curves of single bed and multi bed adsorption column, it is evident that the multi bed adsorption column performs better as the time taken to achieve breakthrough and exhaustion point in multi bed column is 2.5 times and 1.9 times greater than the time taken by single bed adsorption studies respectively.

Higher $\mathrm{R}^{2}$ value and smaller SS value proves that Thomas model was best suitable to explain the adsorption of $\mathrm{Cr}(\mathrm{VI})$ in single and multi bed adsorption column of natural adsorbents rather than Yoon-Nelson model.

Experimental data fitted well with BDST model where $\mathrm{R}^{2}=0.997$. The $k_{a d s}$ and $N_{0}$ values from the BDST model indicate that the adsorbents viz. $\mathrm{CD}, \mathrm{SD}, \mathrm{RH}$ could be used for the removal of $\mathrm{Cr}(\mathrm{VI})$ from synthetic wastewater.

From the cost analysis, multi bed adsorption column is proven to be economical as the mass of adsorbent required to achieve breakthrough is high in single bed adsorption column and hence the treated volume of effluent up to breakthrough for one rupee is less thus resulting in higher treatment cost when compared to multi bed adsorption system.

For every US Dollar spent, multi bed adsorption column is 6.8 times more economical as compared to single bed adsorption column under the same working conditions.

\section{Acknowledgements}

This research did not receive any specific grant from funding agencies in the public, commercial, or not-forprofit sectors. The authors would like to thank institutions which helped conduct parameter measurements. The authors also extend their thanks to authors of previously published papers which provided technical insight into the present domain. The authors express their gratitude to Ms. S. Karthika for tendering language editing of this manuscript.

\section{References}

Ajmal, M., Rao, R. A K., Anwar, S., Ahmad, J., \& Ahmad, R. (2003). Adsorption studies on rice husk: Removal and recovery of Cd(II) from wastewater. Bioresource Technology, 86(2), 147-149. https://doi.org/10.1016/S0960-8524(02)00159-1

Aksu, Z., \& Gönen, F. (2004). Biosorption of phenol by immobilized activated sludge in a continuous packed bed: Prediction of breakthrough curves. Process Biochemistry, 39(5), 599-613. https://doi.org/10.1016/S0032-9592(03)00132-8

Alluri, H. K., Ronda, S. R., Settalluri, V. S., Bondili, J. S., Suryanarayana, V., \& Venkateshwar, P. (2007). Biosorption: An eco-friendly alternative for heavy metal removal. African Journal of Biotechnology, 6(25), 2924-2931.

Argun, M. E., \& Dursun, S. (2008). A new approach to modification of natural adsorbent for heavy metal adsorption. Bioresource Technology, 99(7), 2516-2527. https://doi.org/10.1016/j.biortech.2007.04.037

Bharathi, K. S., \& Ramesh, S. P. T. (2013). Fixed-bed column studies on biosorption of crystal violet from aqueous solution by Citrullus lanatus rind and Cyperus rotundus. Applied Water Science, 3, 673-687. https://doi.org/10.1007/s13201-013-0103-4

Bhattacharya, A. K., Mandal, S. N., \& Das, S. K. (2006). Removal of $\mathrm{Cr}(\mathrm{VI})$ from aqueous solution by adsorption onto low cost non-conventional adsorbents. Indian Journal of Chemical Technology, 13, 576-583.

Bishnoi, N. R., Bajaj, M.,Sharma, N., \& Gupta, A. (2004). Adsorption of $\mathrm{Cr}(\mathrm{VI})$ on activated rice husk carbon and activated alumina, 91, 305-307.

Bohart, G. S., \& Adams, E. Q. (1920). Some aspects of the behavior of charcoal with respect To chlorine. Journal of the Chemical Society, 42, 523-544. https://doi.org/10.1021/ja01448a018

Bulut, Y., \& Tez, Z., 2007. Removal of heavy metals from aqueous solution by sawdust adsorption. Journal of Environmental Sciences, 19(2), 160-166. https://doi.org/10.1016/S1001-0742(07)60026-6

Fu, F., \& Wang, Q. (2011). Removal of heavy metal ions from wastewaters: A review. Journal of Environmental Management, 92(3), 407-418.

https://doi.org/10.1016/j.jenvman.2010.11.011

Han, R., Wang, Y., Zhao, X., Wang, Y., Xie, F., Cheng, J., \& Tang, M. (2009). Adsorption of methylene blue by phoenix tree leaf powder in a fixed-bed column: experiments and prediction of breakthrough curves. Desalination, 245(1-3), 284-297. https://doi.org/10.1016/j.desal.2008.07.013

Horisawa, S., Sunagawa, M., Tamai, Y., Matsuoka, Y., Miura, T., \& Terazawa, M. (1999). Biodegradation of nonlignocellulosic substances II: physical and chemical properties of sawdust before and after use as artificial soil. Journal of Wood Science, 45(6), 492-497.

https://doi.org/10.1007/BF00538959

Indian Standards Institution. (2016). Indian standard specification for test sieves (IS:4601962). New Delhi: Indian Standards Institution. 
Jeyaseeli, D. M., \& Ray, S. P. (2010). Physical charecrictics of Coir pith as a funcation of particle size to be used as solliess medium. American-Eurasian Journal of Agricultural \& Environmental Sciences, 9(4), 415-421.

Kadirvelu, K., Thamaraiselvi, K., \& Namasivayam, C. (2001). Removal of heavy metals from industrial wastewaters by adsorption onto activated carbon prepared from an agricultural solid waste. Bioresource Technology, 76(1), 63-65. https://doi.org/10.1016/S0960-8524(00)00072-9

Khan, N. A., Ali, S. I., \& Ayub, S. (2001). Effect of pH on the Removal of Chromium (Cr) (VI) by Sugar Cane Bagasse. Science and Technology, 6, 13-19.

Kumar, P. R. S. (2012). Experimental study on the properties of concrete made with alternate construction materials. International Journal of Modern Engineering Research, 2(5), 30063012.

Kumar, U., \& Bandyopadhyay, M. (2006). Fixed bed column study for Cd(II) removal from wastewater using treated rice husk. Journal of Hazardous Materials, 129(1-3), 253-259. https://doi.org/10.1016/j.jhazmat.2005.08.038

Li, C., \& Champagne, P. (2009). Fixed-bed column study for the removal of cadmium (II) and nickel (II) ions from aqueous solutions using peat and mollusk shells. Journal of Hazardous Materials, 171(1-3), 872-878.

https://doi.org/10.1016/j.jhazmat.2009.06.084

Meena, A. K., Kadirvelu, K., Mishra, G. K., Rajagopal, C., \& Nagar, P. N. (2008). Adsorptive removal of heavy metals from aqueous solution by treated sawdust (Acacia arabica). Journal of Hazardous Materials, 150(3), 604-611.

https://doi.org/10.1016/j.jhazmat.2007.05.030

Memon, S. Q., Memon, N., Shah, S. W., Khuhawar, M. Y., \& Bhanger, M. I. (2007). Sawdust-A green and economical sorbent for the removal of cadmium (II) ions. Journal of Hazardous Materials, 139(1), 116-121.

https://doi.org/10.1016/j.jhazmat.2006.06.013

Mohan, D., \& Singh, K. P. (2002). Single- and multi-component adsorption of cadmium and zinc using activated carbon derived from bagasse - an agricultural waste. Water Research, 36(9), 2304-2318.

https://doi.org/10.1016/S0043-1354(01)00447-X

Mohan, S., \& Sreelakshmi, G. (2008). Fixed bed column study for heavy metal removal using phosphate treated rice husk. Journal of Hazardous Materials, 153(1-2), 75-82. https://doi.org/10.1016/j.jhazmat.2007.08.021

Munaf, E., \& Zein, R. (1997). The use of rice husk for removal of toxic metals from waste water. Environmental Technology, 18(3), 359-362. https://doi.org/10.1080/09593331808616549

Rahman, I. A., Ismail, J., \& Osman, H. (1997). Effect of nitric acid digestion on organic materials and silica in rice husk. Journal of Materials Chemistry, 7(8), 1505-1509. https://doi.org/10.1039/a700823f

Razi, I. A., Khanif, I., Shaharuddin, M., \& Marziah, M. (2004). Physical and chemical properties of coconut coir dust and oil palm empty fruit bunch and the growth of hybrid heat tolerant cauliflower plant. Pertanika Journal of Tropical Agricultural Science, 27(2), 121-133.

Selvi, K. (2001). Removal of Cr(VI) from aqueous solution by adsorption onto activated carbon. Bioresource Technology, 80(1), 87-89. https://doi.org/10.1016/S0960-8524(01)00068-2

Sharma, P., Ayub, S., \& Tripathi, C. (2013). Agro and Horticultural wastes as low cost adsorbents for removal of heavy metals from wastewater. International Refereed Journal of Engineering and Science, 2(8), 18-27.

Shukla, A., Zhang, Y. H., Dubey, P., Margrave, J. L., \& Shukla, S. S. (2002). The role of sawdust in the removal of unwanted materials from water. Journal of Hazardous Materials, 95(1-2), 137-152. https://doi.org/10.1016/S0304-3894(02)00089-4

Srinivasan, K., Balasubramanian, N., \& Ramakrishna, T. V. (1988). Studies on chromium removal by rice husk carbon. Indian Journal of Environmental Health, 30(4), 376-387.

Suemitsu, R., Uenishi, R., Akashi, I., \& Nakano, M. (1986). The use of dyestuff-treated rice hulls for removal of heavy metals from waste water. Journal of Applied Polymer Science, 31(1), 75-83. https://doi.org/10.1002/app.1986.070310108

Tan, W. T., Ooi, S. T., \& Lee, C. K. (1993). Removal of chromium (VI) from solution by coconut husk and palm pressed fibres. Environmental Technology, 14(3), 277-282. https://doi.org/10.1080/09593339309385290

Thomas, H. C. (1944). Heterogeneous ion exchange in a flowing system. Journal of the American Chemical Society, 66(2), 1664-1666. https://doi.org/10.1021/ja01238a017

Vempati, R. K., Musthyala, S. C., Mollah, M. Y. A., \& Cocke, D. L. (1995). Surface analyses of pyrolysed rice husk using scanning force microscopy. Fuel, 74(11), 1722-1725. https://doi.org/10.1016/0016-2361(94)00119-C

Vieira, M. G. A., de Almeida Neto, A. F., Carlos da Silva, M. G., Nóbrega, C. C., \& Melo Filho, A. A. (2012). Characterization and use of in natura and calcined rice husks for biosorption of heavy metals ions from aqueous effluents. Brazilian Journal of Chemical Engineering, 29(3), 619-633. https://doi.org/10.1590/S0104-66322012000300019

Wan Ngah, W. S., \& Hanafiah, M. A. K. M. (2008). Removal of heavy metal ions from wastewater by chemically modified plant wastes as adsorbents: A review. Bioresource Technology, 99(10), 3935-3948.

https://doi.org/10.1016/j.biortech.2007.06.011

Yoon, Y. H., \& Nelson, J. H. (1984). Application of Gas adsorption kinetics I. A Theoretical model for respirator cartridge service life. American Industrial Hygiene Association Journal, 45(8), 509-516. https://doi.org/10.1080/15298668491400197

Yue, Z., Bender, S. E., Wang, J., \& Economy, J. (2009). Removal of chromium $\mathrm{Cr}(\mathrm{VI})$ by low-cost chemically activated carbon materials from water. Journal of Hazardous Materials, 166(1), 74-78. https://doi.org/10.1016/j.jhazmat.2008.10.125

Zwain, H. M., Vakili, M., \& Dahlan, I. (2014). Waste material adsorbents for Zinc removal from wastewater : A comprehensive review. International Journal of Chemical Engineering, 2014. Article ID 347912. https://doi.org/10.1155/2014/347912 